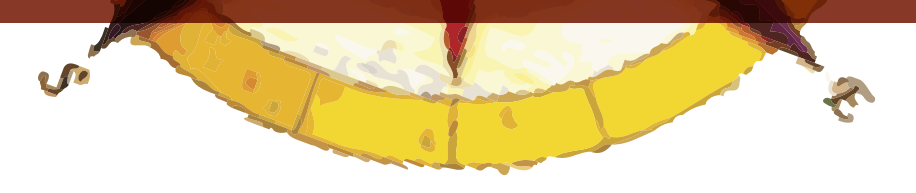

\title{
AS TEMÁTICAS FÍSICO NATURAIS NO ENSINO DE GEOGRAFIA E A FORMAÇÃO PARA A CIDADANIA ${ }^{61}$
}

\author{
Eliana Marta Barbosa de Morais ${ }^{62}$
}

\section{RESUMEN}

El artículo aborda desde la perspectiva de la educación como una práctica social y la construcción del conocimiento basado en el aprendizaje significativo, la importancia de la enseñanza de temas de las características físicas y naturales para la educación cívica. Para la educación geográfica , se argumenta que el enfoque de este tema debe ser en la sociedad actual a través de la superación del listado de fenómenos bio-fisicos a la contextualización de las relaciones sociedad-naturaleza y la dinámica interna de cada uno de ellos y entre ellos. De esta manera la educación puede superar una dicotomía que se ha establecido dentro de la Geografía escolar entre lo biofisico y las acciones humanas.

Palabras Clave: Enseñanza de la Geografía, Temática Físico-natural, Ciudadanía.

\section{RESUMO}

Assentada na perspectiva da educação como uma prática social e na construção do conhecimento com base na aprendizagem significativa, evidenciamos a importância que o ensino das temáticas físico-naturais possui para a formação cidadã. Para que a educação geográfica contemple essa formação, defendemos que a abordagem dessa temática deve ser realizada em meio à contextualização da sociedade atual elencando as relações sociedade-natureza, bem como as dinâmicas internas a cada uma delas e entre elas. Encaminhar o ensino dessa forma permite ultrapassar uma visão dicotômica que tem se estabelecido no interior da Geografia escolar.

Palavras-chave: Ensino de Geografia, Temáticas físico-naturais, Cidadania.

\begin{abstract}
The Scientific and curriculum unity of Geography and of Scholastic Geography of Brazil is the object of reflection of this text. The theoretical and methodological references of analysis are

61 O presente artigo constitui-se em parte dos resultados oriundas da tese O ensino das temáticas fisico-naturais na Geografia escolar, defendida em 2011 no Programa de Pesquisa e Pós-graduação em Geografia da Universidade de São Paulo (USP), sob a orientação da Profa. Dra. Sonia Maria Vanzella Castellar.

62 Professora do curso de Geografia do Instituto de Estudos Socioambientais da Universidade Federal de Goiás (UFG).
\end{abstract}


explained and related to the interpretation of geographical socio-spatial formation. From this perspective, the conception of used territory and concentrated region are organizers of the content and form Geography of Brazil. The proposition of curriculum organization through the themes and the cooperative methodologies of teaching and learning define the content and the form the Scholastic Geography of Brazil. The themes produced by the interaction of science with the socio-historical reality need to be scholastic themes their study must assume the informative purposes, and especially formation of Basic Education.

Key words: Geography of the Brazil, Geography teaching, Basic education.

\section{PRIMEIRAS REFLEXÕES}

Entendemos que o sentido da Geografia no currículo do ensino básico seja sua potencialidade para a formação de cidadãos críticos, autônomos e conscientes para atuarem em sociedade. A Geografia escolar pode contribuir para essa formação ao trabalhar, no ensino, as temáticas físico-naturais do espaço geográfico; todavia, essa contribuição está vinculada à forma como o ensino é encaminhado. Esta forma se relaciona, além de outros fatores, à formação teórico-metodológica do docente que, bem fundamentada, lhe possibilita desenvolver o processo de ensino e aprendizagem a partir da articulação entre objetivos, conteúdos e métodos. Sendo o papel da Geografia escolar o de contribuir para que o estudante compreenda seu cotidiano com base em análises espaciais, evidenciamos que o estudo das temáticas físico-naturais possui um papel significativo a desempenhar para o alcance desse objetivo.

Ao conceber que os conhecimentos relativos às temáticas físico-naturais são importantes para a formação cidadã, cumpre a nós também o papel de explicitar que sua discussão deve ser inserida em patamares que diferencie a abordagem desses temas na Geografia escolar em relação à Geografia acadêmica, bem como a necessidade de ir além do tratamento do conteúdo, valorizando a relação estabelecida entre o conteúdo e a didática assim como propõe Shulman (2001) ao tratar dos conhecimentos didáticos do conteúdo.

Com a intenção de aprofundar a análise acerca dessa relação, selecionamos dentre os temas físico-naturais do espaço geográfico o relevo, as rochas e os solos. Ao selecionarmos esses temas como uma referência para o estudo das temáticas físico-naturais na Geografia escolar, não buscamos entendê-los como elementos isolados, pois acreditamos que, para o entendimento dos processos que envolvem sua origem e a dinâmica atual, é necessário compreender a dinâmica interna e externa. Para isso, é imprescindível a compreensão do papel desempenhado pelo clima, pelo material de origem, pela rede hidrográfica, pelos organismos vegetais e animais e pelo tempo no que se refere a cada um e às interações existentes entre eles. Além desses referenciais, é necessário situar historicamente o ser humano, concebendo-o para além de um ser biológico e de um elemento do sistema, ou seja, como aquele que altera, em diferentes ordens, a dinâmica desses elementos de acordo com o período técnico-científico informacional e com a posição que ocupa no interior do modo de produção.

Para reforçar os argumentos em torno dessa discussão, utilizamos como subsídios as reflexões apresentadas pelos docentes de Geografia das redes municipal e estadual de educação (RME/REE) de Goiânia/Goiás/Brasil, no momento em que realizamos entrevista semiestruturada junto a 60 professores dessas redes e entrevista focal com seis docentes desse coletivo em 2008 e 2009. 


\section{A IMPORTÂNCIA DOS CONTEÚDOS RELEVO, ROCHAS E SOLOS PARA A FORMAÇÃO CIDADÃ}

O principal argumento apresentado em diversas instâncias da sociedade para a inserção ou permanência das disciplinas que compõem o currículo escolar do ensino básico, e entre elas a Geografia, é o de que elas contribuem para a formação do aluno como cidadão. Todavia, vemos sobressair nessas discussões o entendimento de cidadania baseado no aspecto legal e normativo, reduzindo-se, portanto, a condição de cidadania a um status legal, fundamentado nos direitos civis.

É necessário acrescentar a essa concepção de cidadania os demais direitos que a constituem, como o econômico, o social, o cultural, o ambiental, entre outros. Desse modo, destaca-se a importância da participação cidadã, da discussão sobre os temas da distribuição do poder e da problematização das relações sociais. Esses aspectos caminham na direção da transformação social mediante o desenvolvimento do "capital social", conforme expressam Cerda et al. (2004).

Com base nessa concepção, questionamos o papel que a escola vem assumindo na formação do cidadão, partindo do ensino das temáticas físico-naturais do espaço geográfico, em especial, quanto aos temas relevo, rochas e solos. O processo de ensino e aprendizagem que se realiza na instituição escolar, fundamentado nos conhecimentos científicos, deve acompanhar os sujeitos desse conhecimento em seu cotidiano, pois não se separa o sujeito do objeto do conhecimento. Ou seja, não há ou não deve haver um conhecimento para a escola, para os professores, para os pais e outro que se constrói no cotidiano, ambos vistos como conhecimentos isolados. Se esse isolamento se efetiva, ocorre o que Péreze Fernández (2008) denominaram (em nossa tradução) de "simulacro de aprendizagem". Isso significa que o ensino se pauta por uma organização disciplinar tradicional dos conteúdos escolares e por metodologias de ensino repetitivas que não auxiliam os alunos a mobilizar seus próprios conhecimentos para a resolução de problemas "reais", mesmo aqueles colocados em sala de aula. Não há elementos de superioridade entre os conhecimentos cotidianos e científicos, eles se mesclam, estão imbricados, constituem um par dialético por meio do qual o ensino se efetiva.

Acreditamos que a cidadania é favorecida na escola quando ressaltamos o papel que a educação deve cumprir na formação do aluno para que ele possa lutar por seus direitos tendo consciência também de seus deveres. Isso somente será possível se ele compreender a sociedade na qual está inserido.

Assim, é papel da escola, e em especial do professor, ajudar o aluno a construir os conhecimentos que lhe permitam realizar essa ação. Para que isso se efetive mediado pelo ensino das temáticas físico-naturais, os conteúdos relevo, rochas e solos devem ser abordados de forma que compreendam as dinâmicas internas a cada um deles e entre eles, bem como as que se estabelecem com a sociedade. Isso não significa que, se ele souber estes conteúdos já pode ser considerado um cidadão, pois tais conteúdos não representam a totalidade, mas parte dela, uma vez que há outros elementos que a compõem. Todavia, sem esse conhecimento o aluno não exerce a cidadania em sua totalidade, pois seu cotidiano também é lido, compreendido com base na relação que ele estabelece com esses temas - a relação entre o todo e as partes. Com essa compreensão, o aluno tem condições de ler o mundo relacionando o físico-natural com o social. É possível, por exemplo, compreender os motivos pelos quais ocorre a ocupação de áreas de risco e por que essas áreas se configuram como tais, compreender os diferentes valores atribuídos ao solo, seja em área urbana ou não, e quais as relações que se estabelecem com as características do relevo e outras questões por eles mesmos problematizadas no seu cotidiano com base nos conhecimentos construídos. 
Para que isso seja possível, deve ser desenvolvida na escola uma prática que permita questionar, que incorpore o interesse dos alunos, que produza a capacidade de pensar sustentada pela criatividade e pela autoria de pensamento (Callai, 2001). Os conhecimentos prévios dos alunos devem ser considerados pelo professor com o intuito de alcançar um saber sistematizado.

A concepção de inércia na qual os temas físico-naturais aparecem como base, como substrato físico para a ocupação humana, deve ser contraposta às dinâmicas que comumente visualizamos no cotidiano ou através dos canais de informação. Assim, da mesma forma que podemos mobilizar os conhecimentos prévios dos alunos sobre tsunamis e vulcões para falar do movimento realizado pelas placas tectônicas, é possível utilizar as estradas para falar dos divisores de água, ou os movimentos de massa para falar da vertente.

Portanto, os docentes têm uma importância central para auxiliar os alunos com vistas à formação cidadã. Nessa atuação, destacam-se os conhecimentos didáticos do conteúdo. Portanto, para que a escola possa favorecer a formação cidadã dos sujeitos envolvidos, o professor deve possuir uma formação sólida em sua área de atuação na qual os conhecimentos específicos e didáticos estejam articulados, pois "[...] o processo de ensino se inicia necessariamente numa circunstância em que o professor compreende aquilo que se há de aprender e como se deve ensinar" (Shulman,2001, p. 173). Isso, com os demais elementos que compõem o conhecimento docente, a exemplo do conhecimento dos alunos e dos contextos educativos, favorece o processo de ensino e de aprendizagem.

Reconhecendo que a motivação dos alunos, ou sua disposição para aprender, está relacionada, entre outros fatores, com temas relevantes da contemporaneidade, consideramos que o ensino das temáticas físico-naturais do espaço geográfico cumpre este papel. O professor, ao problematizar esses conteúdos com base em questões socialmente relevantes, contribuirá para que eles se tornem atrativos e significativos para os alunos, de modo que os integrem aos seus conhecimentos. É possível motivar partindo das temáticas relacionadas ao cotidiano, porém os professores precisam dominar os conhecimentos geográficos e didáticos específicos.

Diariamente constituem manchetes de revistas, jornais e páginas da internet problemas que envolvem a abordagem desta temática. Todavia, predominam informações que os apresentam como oriundos de fatores naturais ou divinos, a-históricos, abstratos e sem ligação concreta com a realidade vivenciada pelos estudantes.

Portanto, apresentar, discutir, problematizar com os alunos as questões em torno dos temas físico-naturais englobando as relações sociedade-natureza são ações que contribuem para ampliar as discussões sobre cidadania, incorporando, além das questões de cunho econômico e legal, aquelas relativas à justiça social.

A Geografia, como uma disciplina formativa, necessita fornecer instrumentos para que os alunos exerçam sua cidadania. A questão central para o encaminhamento do ensino com mais qualidade é possibilitar que os alunos, fundamentados num sólido aparato teórico-conceitual, posicionem-se ante os problemas que enfrentam no seu cotidiano, seja no trabalho, em casa, na escola ou em outros espaços que frequentam.

Há muito tempo tem sido debatida a importância de ensinar, em Geografia, as temáticas físico-naturais do espaço geográfico. Elas são de importância fundamental para a formação dos alunos e 
os problemas acerca de seu ensino podem estar relacionados ao desconhecimento desses conteúdos no que se circunscreve tanto aos conteúdos em si como aos referenciais teórico-metodológicos e/ou a problemas relativos ao seu encaminhamento considerando o processo de ensino e aprendizagem na Geografia escolar.

Nas pesquisas desenvolvidas nas áreas de metodologia do ensino, existe uma tendência de reconhecimento da necessidade de utilizar-se o cotidiano como referência para a construção do conhecimento. Será que o processo de ensino e de aprendizagem encaminhado na Geografia escolar acerca dessas temáticas tem utilizado o cotidiano do aluno como referência?

O cotidiano do aluno é repleto de referências sobre as temáticas físico-naturais. Mais que concebê-las como o substrato inerte em que se situa a escola, a casa ou o bairro, é preciso evidenciar que há uma evolução do relevo, das rochas e dos solos e que a sociedade, estruturada em classes sociais e com um modo de produção excludente e segregador, impõe uma nova dinâmica, seja intensificando os processos existentes ou criando outros.

Assim, com o objetivo de compreender o ensino desta temática nas aulas de Geografia, perguntamos aos professores da RME e da REE de Goiânia, durante a entrevista focal ${ }^{63}$, se para eles o ensino das temáticas físico-naturais do espaço geográfico favorece a formação do aluno como um cidadão e por quê. Os professores foram unânimes em dizer que sim. Dois professores justificaram que o ensino desta temática é importante:

[...] Se eu ensino para ele porque ele não pode morar ali no 'buracão' eu ajudo o aluno a entender isso. Ensino a Lei: é ilegal morar ali, é uma área de preservação permanente. É por isso que vocês foram retirados de lá. (Prof. RME $/ 5^{64}$ ).

[...] para que ele tenha consciência de que existem as condições naturais e que existe uma política que pensa essas condições naturais. Por que eu moro numa área de risco? Para eles terem noções de para que serve o ensino sobre o relevo. Para saber o risco dele com a família dele. (Prof. RME/10).

Para que o aluno tenha consciência de que as determinações políticas levam em conta as características físico-naturais do espaço geográfico [ou precisam levá-las], ele deve compreender essas características. Assim, poderá examinar os motivos pelos quais as decisões políticas se encaminham de uma ou outra maneira e tomar suas próprias deliberações, pautando-se pelo direito de cidadania que ele e a população como um todo possuem.

Se este conteúdo é considerado importante para a formação da cidadania, ele deve ser ensinado na escola. Para isso são necessários objetivos claros, inovação nos procedimentos didáticos utilizados e referenciais teórico-metodológicos consistentes.

Por isso, perguntamos, durante as entrevistas semiestruturadas ${ }^{65}$, aos professores da RME e da

63 Circunscreveu-se à entrevista que realizamos com seis professores que haviam participado das etapas anteriores utilizadas para a obtenção dos dados empíricos.

64 Para resguardar a identidade dos professores, sujeitos da pesquisa, eles foram enumerados de 1 a 60 , de acordo com as entrevistas semiestruturadas realizadas, seguidas das siglas RME, REE ou ambas, para fazer referência à esfera de trabalho dos professores. 
REE de Goiânia sobre os objetivos que pretendem alcançar quando ensinam estes conteúdos para seus alunos. O maior percentual das respostas recebidas justifica o ensino do conteúdo por si mesmo. Essa ideia está contida na afirmação de 18 professores, o que representa $30 \%$ das respostas obtidas (Gráfico 1).

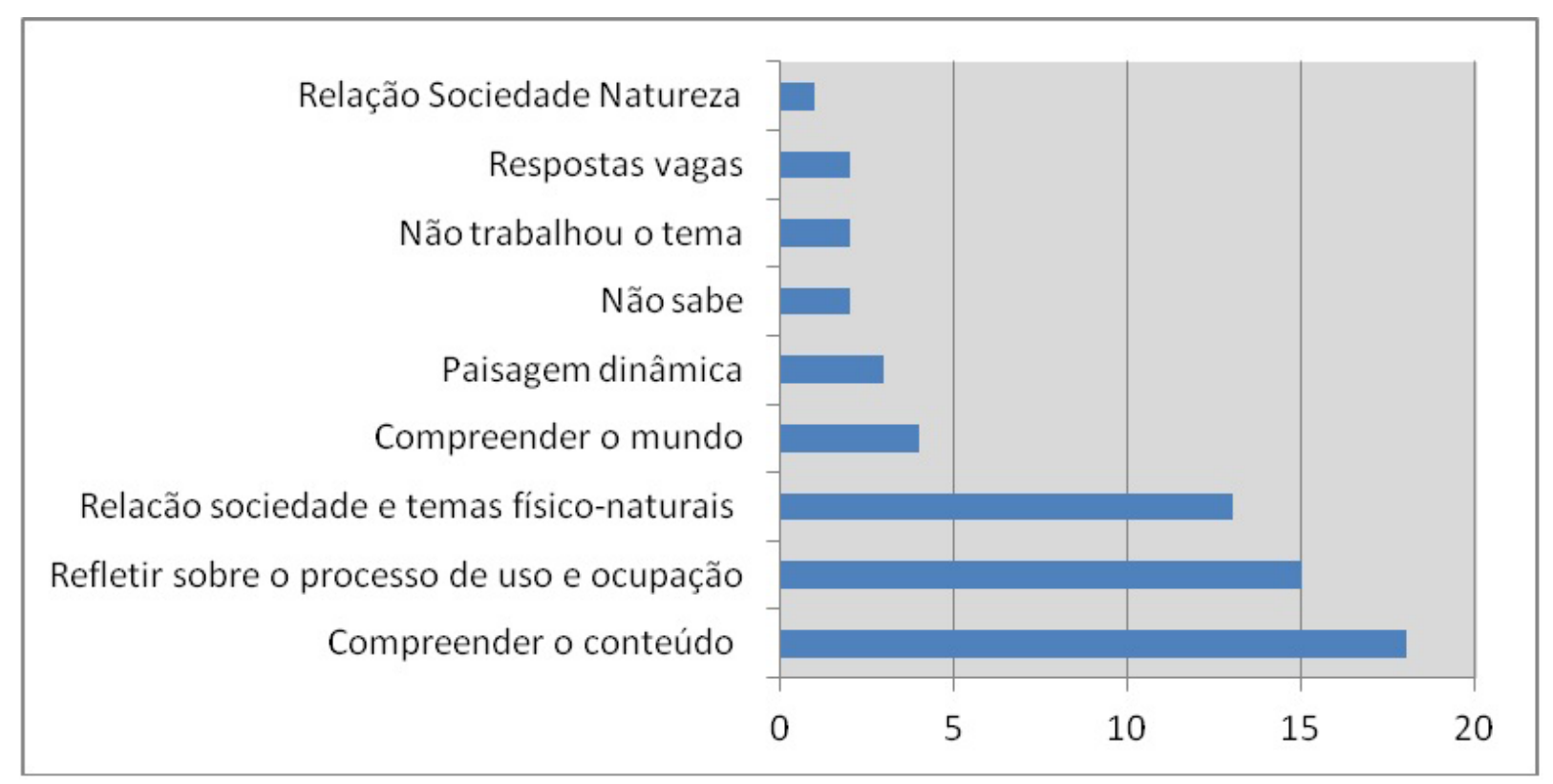

Gráfico 1. Objetivos do processo de ensino e aprendizagem para os conteúdos relevo, rochas e solos. Fonte: Entrevistas semiestruturadas elaboradas por Eliana Marta Barbosa de Morais, 2008-2009.

Dentre os objetivos que pretendem alcançar, dois professores apontaram os seguintes:

Compreender o processo de formação do relevo, os diferentes tipos de rochas e sua ocorrência nos diferentes relevos, [...] processos de formação dos solos. (Prof. RME/12).

Que eles aprendam. Que entendam o que estou falando. (Prof. RME/REE/59).

Destacou-se por aparecer 15 vezes (25\%) a justificava da necessidade de refletir sobre o processo de uso e ocupação, em razão da importância de preservar e respeitar o ambiente e da percepção dos impactos causados pela ação humana, como expressam estes professores:

Maior responsabilidade no uso e ocupação do espaço. (Prof. RME/REE 57).

Principalmente no que diz respeito à preservação ambiental. É onde eles moram, têm seus filhos, seus netos. Tem que cuidar da preservação ambiental. (Prof. RME/REE/48).

Outro aspecto destacado pelos professores foi a importância de compreender a relação que o ser humano estabelece com esses temas, segundo 13 professores, isto é, 21,67\% (Gráfico 38), o que pode ser observado nas seguintes falas:

mos como critérios para selecionar os professores entrevistados: serem licenciados em Geografia e concursados em uma ou em ambas as redes de ensino, estarem ministrando ou já haverem ministrado aulas no ano letivo de 2008 na cidade de Goiânia e que as escolas nas quais estivessem trabalhando fossem distribuídas nas diferentes regiões de Goiânia 
Compreensão da dinâmica da Terra e sua relação com o homem. (Prof. REE/10).

Objetivo maior é eles perceberem a importância do solo, propriamente dito e como a humanidade utiliza esse solo. (Prof. RME/REE/60).

Considerando tais objetivos, podemos dizer que não há como pensar o ensino desta temática desconectado de uma concepção de Geografia. Concebemos os conteúdos ensinados na escola como "instrumentos" que os alunos utilizam para dialogar com sua realidade dentro e fora da escola. Portanto, ao possibilitar a aquisição de conhecimentos e habilidades, o ensino desta temática auxilia os alunos na formação de conceitos que os preparam para situações de seu cotidiano que extrapolam aquelas já desenvolvidas em sala de aula.

Assim, o ensino sobre relevo, rochas e solos deve ajudá-los a refletir, por exemplo, sobre os motivos pelos quais há processos erosivos ou áreas frequentemente inundadas em determinado lugar, quem são os sujeitos que sofrem ou não com essas situações ou por que as áreas de cerrado estão sendo ocupadas intensivamente desde a década de 1970.

Para ensinar esses conteúdos em sala de aula, 50 professores $(83,33 \%)$ disseram que os associam com o cotidiano do aluno com o intuito de facilitar a sua compreensão (Gráfico 2).

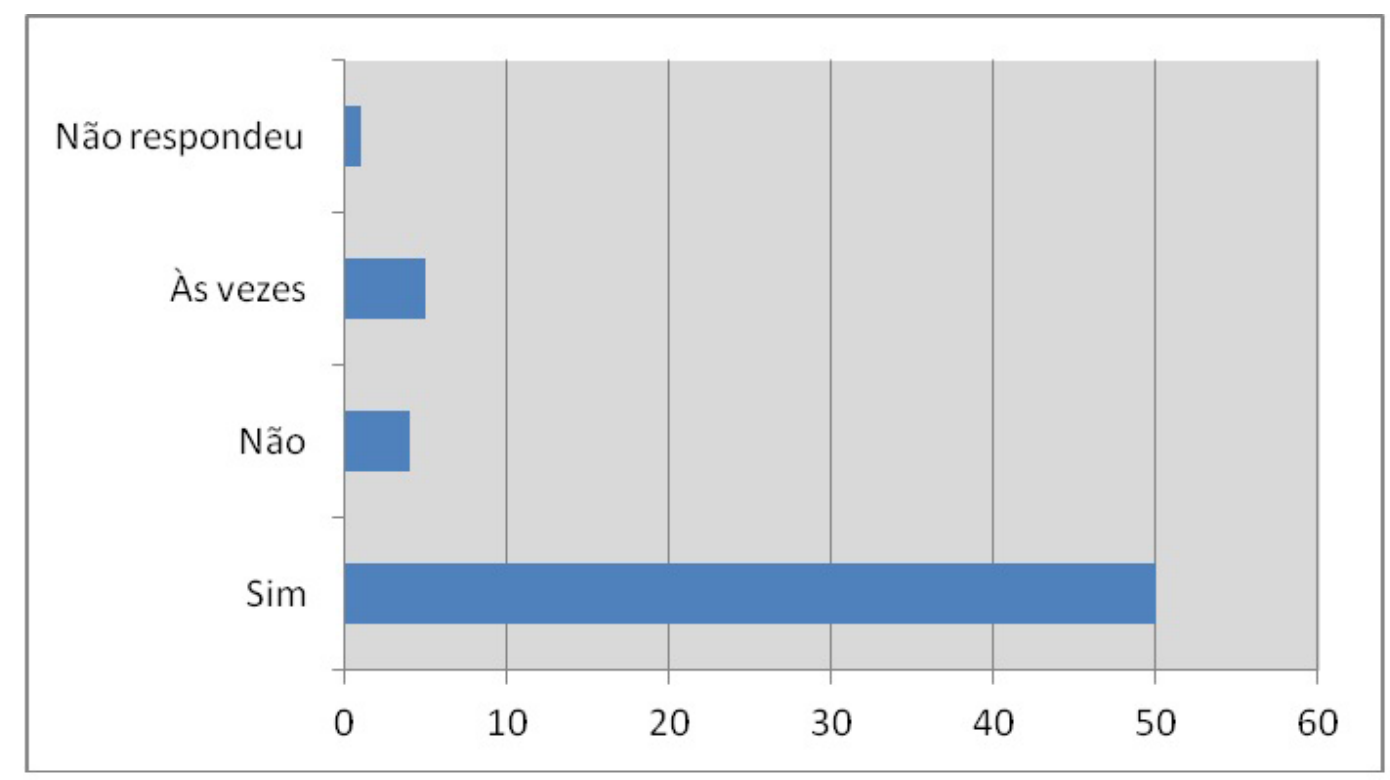

Gráfico 2. Associação entre o cotidiano e o ensino de relevo, rochas e solos.

Fonte: Entrevistas semiestruturadas elaboradas por Eliana Marta Barbosa de Morais, 2008-2009.

$\mathrm{O}$ fato foi comumente apresentado por meio de exemplos de lugares que os alunos conhecem ou de situações vivenciadas por eles. As falas de dois professores retratam essa prática:

Ah! é lógico. Geralmente quando você fala de solos os alunos falam da fazenda que conhecem, da cor do solo, mas não é nada científico, provado, é só conversa mesmo. (Prof. RME/7).

Trabalho. Associo. Eu começo a partir daqui, que tipo de relevo tem aqui. Eu sempre associo, mas não tem muito material. Eu faço só com o relevo. Com rocha e solo é bem mais superficial. (Prof. RME/REE/54).

Apenas quatro professores $(6,67 \%)$ informaram que não relacionam este conteúdo com o coti- 
diano deles e dos próprios alunos e cinco $(8,33 \%)$ disseram fazer essa relação de forma incipiente e em poucas ocasiões.

Segundo Cavalcanti (1998), é preciso mobilizar o cotidiano do aluno e refletir sobre ele pela confrontação com o conhecimento científico. Não se trata apenas de uma formalidade, os professores devem trabalhar com os conhecimentos prévios dos alunos e o conhecimento científico, confrontando-os e complementando-os, de modo que nenhum seja secundarizado.

É preciso que haja investimento na formação do professor que redunde num planejamento eficaz para o trabalho em sala de aula. Embora a formação inicial seja a base para o trabalho desenvolvido pelos professores no cotidiano escolar, ela por si só não é suficiente para a garantia de um ensino de qualidade. $\mathrm{Na}$ escola, os conhecimentos trabalhados extrapolam aqueles oriundos da formação inicial, somando-se a isso o fato de que a evolução da ciência exige novas formas de conceber os conteúdos. Portanto, os professores precisam continuar seu processo de formação e isso depende também deles, visto que requer investimento pessoal e financeiro.

Questionamos os professores da RME e da REE de Goiânia sobre como eles avaliam a consecução de seus objetivos no ensino da temática em pauta. Das respostas, destacamos as seguintes formas de avaliação: pela argumentação, postura e participação dos alunos, com 31 indicações $(32,98 \%)$; pela aplicação de prova, com 27 citações $(28,73 \%)$ e pela realização de atividades, com 22 indicações ou 23,41\% (Gráfico 3).

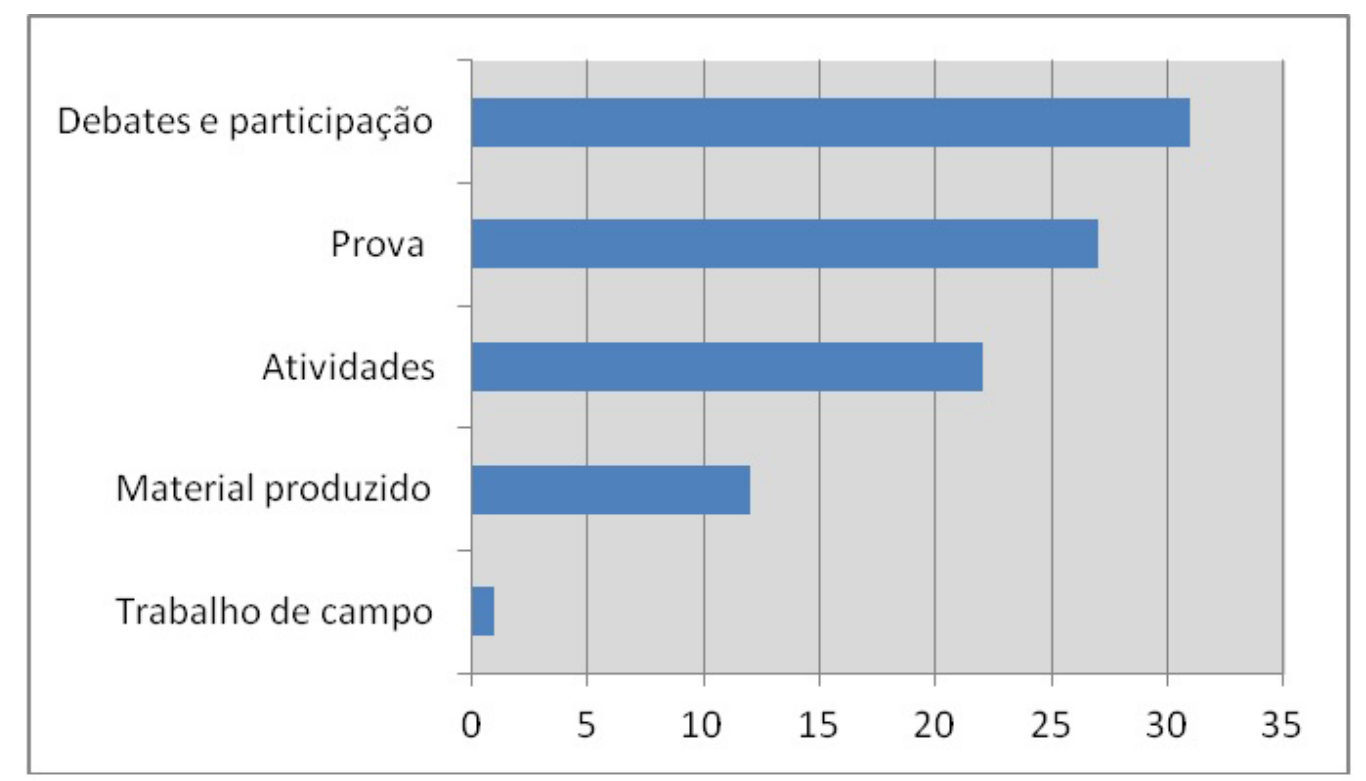

Gráfico 3. Formas de avaliar se os objetivos foram alcançados ao ensinarem relevo, rochas e solos. Fonte: Entrevistas semiestruturadas elaboradas por Eliana Marta Barbosa de Morais, 2008-2009.

Embora esse conjunto de elementos possa indicar a realização de uma avaliação contínua, Rabelo (2010), ao observar aulas e analisar as práticas avaliativas de um grupo formado por parte desses professores, constatou que a avaliação realizada por eles ainda se dá por meio de práticas tradicionais. Uma avaliação realizada assim pode se converter num instrumento ineficaz, que não ajuda o professor a diagnosticar os conhecimentos que os alunos possuem sobre a temática ou as dificuldades enfrentadas ao longo da sequência didática. 
Indagados sobre o que acham de ensinar os conteúdos relevo, rochas e solos, 44 professores (73,33\%) que atuam na RME e/ou na REE de Goiânia responderam que tal conteúdo é importante, o que torna relevante seu ensino, e 7 professores $(11,67 \%)$ não o consideraram importante, destacando como uma de suas justificativas o fato de não gostarem do conteúdo (Gráfico 4).

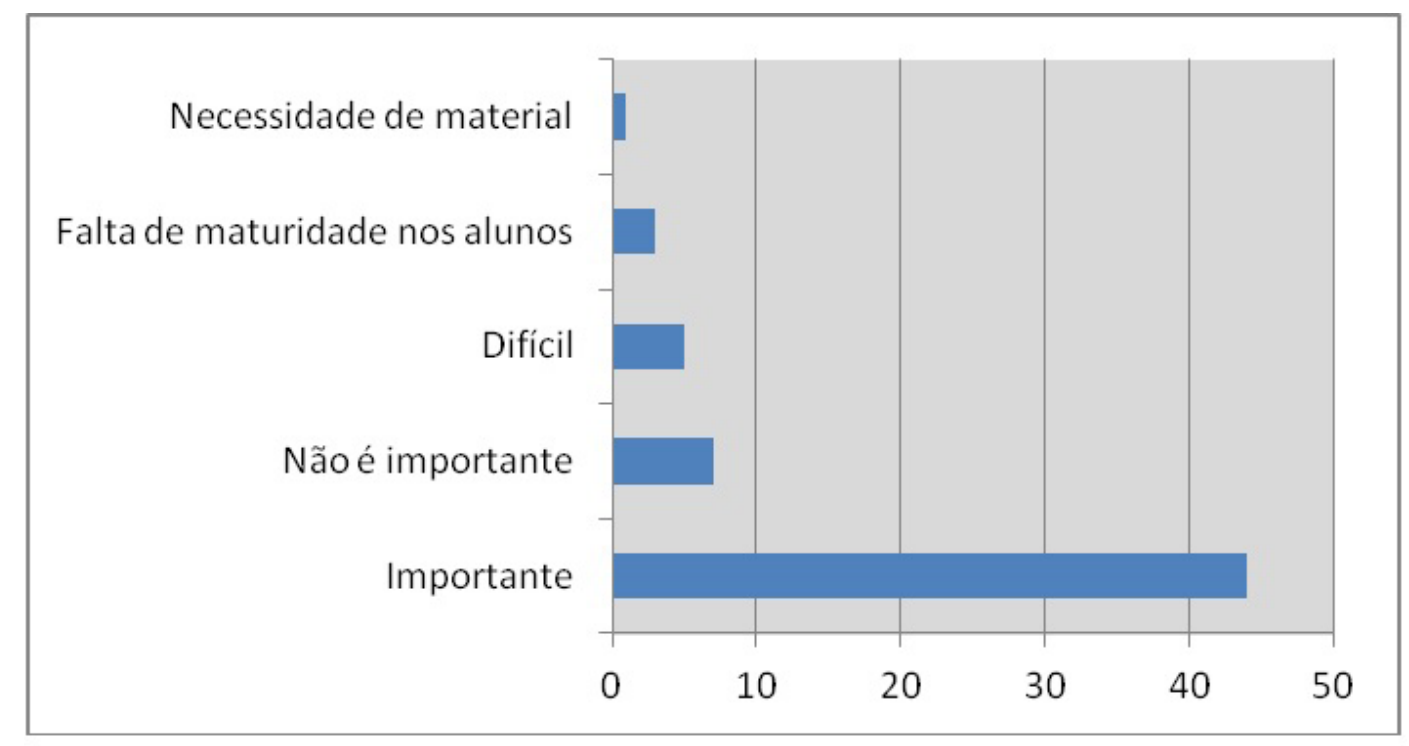

Gráfico 4. O que os professores de Geografia entrevistados acham sobre ensinar o conteúdo relevo, rochas e solos.

Fonte: Entrevistas semiestruturadas elaboradas por Eliana Marta Barbosa de Morais, 2008-2009.

Algumas das respostas a esse questionamento podem ser observadas a seguir:

Eu acho que seria primordial, o importante mesmo [...]. Os alunos questionam por que em períodos de chuva tem lugares em Goiânia que alagam. (Prof. RME/7).

Gosto, pois eu acho importante eles entenderem os aspectos físicos que eles vivenciam todos os dias, mas que por vezes passam despercebidos. (Prof. RME/12).

Eu acho importante, porém mais difícil do que trabalhar globalização. Mas é necessário que eles tenham essa compreensão. (Prof. RME/REE/60).

Eu não gosto muito não. Eu acho muito vago. Não sei como a gente trabalha, parece que falta alguma coisa para eles assimilarem melhor. (Prof. REE/28).

Chato de ensinar. Eles não entendem isso. (Prof. REE/38).

Com base nas três primeiras citações, vemos a necessidade de mobilizar os conhecimentos oriundos especialmente da formação inicial para identificar os fatores que justificam o alagamento e a parcela da sociedade mais atingida por fenômenos dessa natureza; além disso, encaminhar reflexões sobre as temáticas físico-naturais. Quanto às duas últimas referências, observamos um descompasso entre o conhecimento geográfico e a didática da Geografia ou mesmo o desconhecimento desses referenciais ao tratar dessa temática.

Quando perguntamos aos professores sobre a motivação dos alunos diante desta temática, 34 profissionais $(56,67 \%)$ da RME e da REE disseram acreditar que seus alunos gostam do conteúdo (Gráfico 5), conforme revela a resposta dos professores, apresentadas a seguir: 
[...] eles gostam muito desse conteúdo, não só desses, mas de Geografia. [...]. Talvez o jeito que eu trabalho, o que leva eles a refletir o que eles veem na atualidade. (Prof. RME/2).

Gostam, porque eles são atenciosos, eles perguntam, se interessam e para eles isso aí eles conseguem imaginar isso na prática. Quando falo sobre solo, terra, vegetação. (Prof. RME/REE/48).

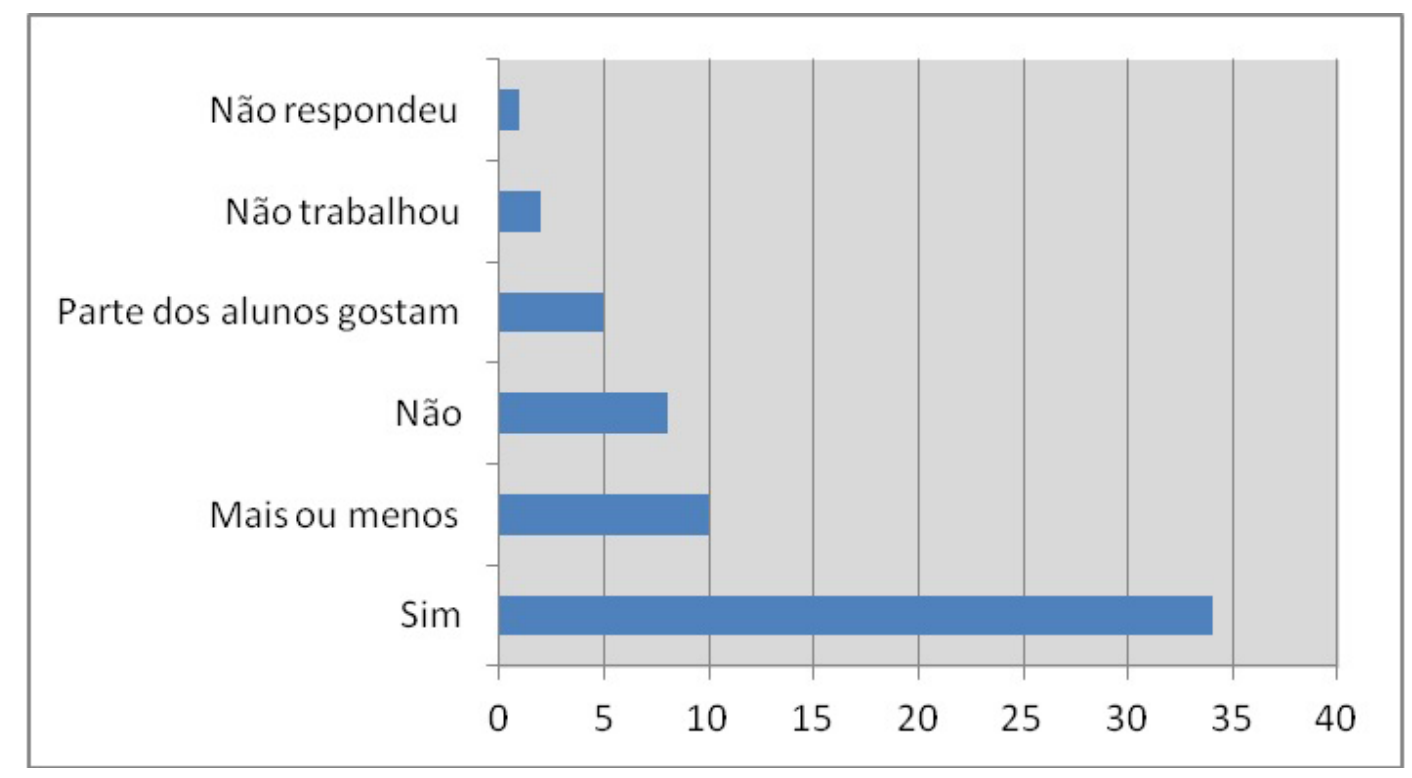

Gráfico 5. Concepção dos professores de Geografia entrevistados sobre o gosto dos alunos pelo conteúdo relevo, rochas e solos.

Fonte: Entrevistas semiestruturadas elaboradas por Eliana Marta Barbosa de Morais, 2008-2009.

Dez professores destacaram que os alunos gostam mais ou menos, como se vê nos exemplos:

Mais ou menos. Porque é só parte física e muita teoria. (Prof. REE/30, grifos nossos.).

Não muito. Porque eles acham que não está tão ligado. Embora a gente tente mostrar a interferência do homem. Isso aí a gente percebe quando ele está fazendo um exercício, eles têm dificuldades para encontrar as respostas. (Prof. RME/17, grifos nossos.).

Entre os entrevistados, dez (16,67\%) afirmaram que os alunos não gostam do conteúdo (Gráfico $5)$.

Normalmente eu acho que não. É um conteúdo maçante (Prof. REE/39, grifos nossos.).

Não gostam muito. Me parece que para ele está muito distante do que ele está vivendo. Em geral eles não gostam de Geografia. A maioria dos alunos pergunta se eu vou passar resumo. Eu digo que não. No $8^{\circ}$ ano eles gostam mais, no $6^{\circ}$ ano é diferente. (Prof. RME/REE/5. grifos nossos.).

Acreditamos que uma das justificativas para os alunos não gostarem deste conteúdo está relacionada ao modo como seu ensino é encaminhado, especialmente aos referenciais teórico-metodológicos mobilizados pelos docentes, o que pode ser observado nos grifos que fizemos nas citações. Assim, quando seu ensino é realizado sem conexão com os conhecimentos prévios dos alunos, com seu cotidiano e com uma abordagem apenas teórica e distante da construção do conhecimento, ele realmente não tem sentido para os alunos, portanto, não desperta seu interesse. É necessário ampliarmos as reflexões sobre o ensino desta temática de modo que parta de questões significativas que estejam amparadas no cotidiano do aluno. Todavia, para compreendê-las, é necessário trabalhar 
também com a dinâmica intrínseca a cada um desses elementos físico-naturais e com as relações que se estabelecem entre eles, na perspectiva da morfoescultura e da morfoestrutura, pois é esse conjunto de conhecimentos que permite ao aluno tecer um diálogo mais profícuo com a realidade da qual faz parte.

\section{CONSIDERAÇÕES FINAIS}

Se a maioria dos professores considera importante o ensino destes temas para a formação da cidadania, o questionamento a ser encaminhado para reflexões futuras é: Como os professores ensinam as temáticas físico-naturais e, especialmente, quais conhecimentos os docentes mobilizam para ensiná-las de modo que seja factível aferir os possíveis desdobramentos que seu ensino pode ter socialmente?

Encaminhar o ensino dessa temática na Geografia escolar requer a mobilização de conhecimentos que evidenciem a dinâmica e a relação existente entre os temas ora apresentados, considerando na perspectiva das múltiplas escalas temporais e espaciais a compreensão dos processos morfoesculturais e morfoestruturais, associados ao conhecimento didático do conteúdo.

\section{BIBLIOGRAFIA}

Callai, H. C. (2001). A Geografia e a escola: muda a geografia? Muda o ensino? In: AGB - Associação dos Geógrafos Brasileiros. Paradigmas da Geografia - Parte I. Revista Terra Livre, (16), p. 133-152, 2001.

Cavalcanti, L. S. (1998). Geografia, escola e construção de conhecimentos. São Paulo: Papirus.

Cerda, A. M. et al. (2004). El complejo camino de la formación ciudadana. Una mirada a las prácticas docentes. Santiago: LOM Ediciones.

Pérez, F. F. G; Fernandez, N. A. (2008) ¿Puedes la escuela del siglo XXI educar a los ciudadanos y ciudadanas del siglo XXI? Diez años de cambios en el Mundo, en la Geografía y en las Ciencias Sociales, 1998-2008. In: Actas del X Coloquio Internacional de Geocrítica. Universidade de Barcelona.Disponível em: <http://www.ub.es/geocrit/-xcol/394.htm>. Acesso em: $30 \mathrm{abr}$. 2009.

Rabelo, K. S. P. (2010). Ensino de Geografia e avaliação formativa da aprendizagem: experiências e princípios na rede pública de Goiânia-GO. Dissertação (Mestrado). Instituto de Estudos Socioambientais, Universidade Federal de Goiás, Goiânia.

Shulman, L. S. Conocimiento y enseñanza. (2001). Revista Estudios Públicos, Chile, 83.

Artículo recibido 20 - 09 - 11. Aprobado 25 - $11-11$. 